\title{
DISSOLUTION KINETICS OF PARTIALLY PURIFIED BROMELAIN FROM PINEAPPLE CORES (ANANAS COMOSUS [L.] MERR.) ENCAPSULATED IN GLUTARALDEHYDE-CROSSLINKED ALGINATE-GUAR GUM
}

\author{
FAKHRIAN JULIANO, HEGI ADI PRABOWO, EMIL BUDIANTO, SISWATI SETIASIH, SUMI HUDIYONO*
}

Department of Chemistry, Faculty of Mathematics and Natural Sciences, Universitas Indonesia, Depok 16424, West Java, Indonesia. Email: sumi.hudiyono@sci.ui.ac.id

Received: 15 December 2019, Revised and Accepted: 06 January 2020

\section{ABSTRACT}

Objective: Bromelain is susceptible to low pH and thus must be encapsulated in glutaraldehyde-crosslinked alginate-guar gum (Alg-GG) hydrogels to avoid bromelain activity degradation in the stomach.

Methods: Isolated crude bromelain was purified through ammonium sulfate precipitation, sodium benzoate precipitation, and dialysis. Bromelainloaded Alg-GG was dissolved in artificial gastric fluid and intestinal environment.

Results: The bromelain fractions showed a higher specific activity (U/mg) than the crude enzyme (51.32), as follows ammonium sulfate fraction (267.70 \pm 4.67$)$, sodium benzoate fraction $(115.63 \pm 3.35)$, and dialysis fraction (332.22). The dialysis fraction was encapsulated in Alg-GG hydrogel containing $0.75 \%(\mathrm{v} / \mathrm{v})$ glutaraldehyde through the post-loading method. The swelling ratios of the hydrogel are $188.43 \%$ at $\mathrm{pH} 1.2$ and $563.83 \%$ at $\mathrm{pH}$ 7.4. The highest encapsulation efficiency is $72.2 \%$. The maximum bromelain concentration released during dissolution is higher in artificial intestinal environment $(1.97 \mathrm{mg} / \mathrm{L})$ than in artificial gastric fluid $(0.18 \mathrm{mg} / \mathrm{L})$, and the maximum proteolytic activities are 1.3 and $0.15 \mathrm{U} / \mathrm{mL}$, respectively. Data were incorporated into the zero-order, first-order, Higuchi, and Korsmeyer-Peppas models to determine the kinetics and mechanism of bromelain dissolution. All bromelain concentrations (70,140, and $210 \mathrm{ppm}$ ) follow the Korsmeyer-Peppas model. The dissolution mechanism is a combination of diffusion and erosion. Both the dialysis fraction (56.59\%) and the dissolution product (47.45\%) showed a good in vitro antiplatelet activity.

Conclusion: The present data show the promise of Alg-GG encapsulation as a vehicle for orally administered therapeutic enzymes.

Keywords: Bromelain, Encapsulation, Alginate-guar gum, Dissolution, Kinetics.

(c) 2020 The Authors. Published by Innovare Academic Sciences Pvt Ltd. This is an open access article under the CC BY license (http://creativecommons. org/licenses/by/4. 0/) DOI: http://dx.doi.org/10.22159/ajpcr.2020.v13i3.36629

\section{INTRODUCTION}

Cardiovascular disease (CVD) is the most common cause of death in all ages, accounting for $37 \%$ of deaths in Indonesia [1]. CVD usually involves abnormal blood aggregation, in which platelet or thrombocyte plays an important role. Excessive platelet aggregation (thrombus) can cause several health issues such as ischemic heart disease, venous thromboembolism, and stroke [2]. Many drugs have been developed to inhibit cyclooxygenase, which acts as a catalyst for thromboxane A2 formation [3]. Thromboxane A2 plays important role in platelet aggregation process. Aspirin is widely used for this purpose. However, long-term use of this drug has several side effects such as nausea, headache, and gastrointestinal bleeding [4]. Therefore, an herbal active agent is needed to replace the abovementioned drug.

Indonesia is a tropical country that is rich in natural sources, especially agricultural products. For instance, pineapple was one of the highly produced annual fruit plants in Indonesia in 2016 and 2017, with a production growth of $28.64 \%$ [5]. However, when these pineapples are canned, the pineapple cores, which contain bromelain, are discarded in the process.

Bromelain consists of endopeptidase enzyme, which bears a sulfhydryl group at its active site. Bromelain can reduce platelet aggregation, plaques in artery, and blood coagulation in CVD [6]. As an oral drug, bromelain interacts with the gastric fluid, which significantly reduces bromelain activity within the first $4 \mathrm{~h}$ [7]. Intestine is the best place to absorb bromelain without degradation and losing their activity [8]. Hence, to protect the bromelain from the gastric fluid and to control its release, we encapsulated the bromelain in a $\mathrm{pH}$-sensitive hydrogel, namely, glutaraldehyde-crosslinked alginate-guar gum (Alg-GG). The ability of this hydrogel to act as a drug delivery system can be described based on its mechanism and kinetics of dissolution, which are determined using several mathematical models. In this study, the mathematical models used include the zero-order, the first-order, the Higuchi, and the Korsmeyer-Peppas models [9]. By inputting into these models the data obtained during the dissolution test conducted in an artificial gastric fluid ( $\mathrm{pH} 1.2)$ and in an artificial intestinal environment ( $\mathrm{pH}$ 7.4), we could obtain the linearity of regression plot $\left(\mathrm{R}^{2}\right.$ value) and determine the most suitable model [10]. In addition, the hydrogel was characterized by Fourier-transform infrared (FTIR) spectroscopy, scanning electron microscopy (SEM), and optical microscope to validate the data.

\section{METHODS}

Plant sample

The pineapple fruits used in this study were purchased from a traditional market in Jakarta, Indonesia.

Bromelain isolation, salt precipitation, and dialysis Bromelain was isolated, precipitated, and dialyzed as previously described [11]. The proteolytic activity of bromelain during salt precipitation was compared with that of ammonium sulfate and sodium benzoate (at $0-20 \%, 20-50 \%$, and $50-80 \%$ concentrations for both).

Determination of protein contents and proteolytic activities The total protein contents of bromelain were determined at $595 \mathrm{~nm}$ using a ultraviolet (UV)-visible spectrophotometer according to the 
Lowry and Bradford method. The proteolytic activities of the fractions were determined at $280 \mathrm{~nm}$ absorbance according to the Kunitz method [12].

\section{Synthesis of Alg-GG hydrogel beads}

Alg-GG hydrogel beads were synthesized by mixing $1.5 \mathrm{~g}$ sodium alginate and 0.5 g guar gum into $80 \mathrm{~mL}$ water. The Alg-GG solution was stirred at room temperature until the mixture became homogenous; subsequently, different concentrations of a cross-linking agent $0.75 \%$, $1.00 \%$, and $1.25 \%(\mathrm{v} / \mathrm{v}$ ) glutaraldehyde) were added. The total volume of the mixture was adjusted to $100 \mathrm{~mL}$ using aqua dest and then stirred at room temperature for $12 \mathrm{~h}$. The homogenous solution of Alg-GG was subsequently added in $0.5 \mathrm{M} \mathrm{CaCl}_{2}$ using an infusion set and allowed to stand for a week to produce stable beads. The Alg-GG hydrogel beads were filtered and then washed with aqua dest to remove the excess glutaraldehyde and $\mathrm{CaCl}_{2}$. Finally, the Alg-GG hydrogel beads were dried at $50^{\circ} \mathrm{C}$ and stored in a desiccator before FTIR analysis [13].

\section{Determination of swelling ratios}

The dry Alg-GG hydrogel beads were weighed and soaked in $5 \mathrm{~mL}$ hydrochloric acid-potassium chloride ( $\mathrm{HCl}-\mathrm{KCl}$ ) buffer $\mathrm{pH} 1.2$ and $6 \mathrm{~mL}$ phosphate buffer $\mathrm{pH} 7.4$ for $30 \mathrm{~min}$ at room temperature. The remaining water on the surface of the hydrogel was removed using a blotting paper. The wet weight of the Alg-GG hydrogel was also determined, and the swelling ratios were calculated as follows [14]:

$$
\text { Swelling ratio }(\%)=\frac{\mathrm{W}_{\text {wet }}-\mathrm{W}_{\mathrm{dry}}}{\mathrm{W}_{\mathrm{dry}}} \times 100 \%
$$

\section{Bromelain encapsulation in Alg-GG hydrogel}

Dry Alg-GG hydrogel beads were soaked in a fraction of bromelain dialysis solution for an hour at room temperature. Next, the hydrogel beads were obtained and washed with aqua dest to remove the excess bromelain on their surfaces. The protein contents and proteolytic activities of initial bromelain solution, the remaining solution, and the dishwater solution were determined to calculate the encapsulation efficiency. The hydrogel beads loaded with bromelain were freeze-dried and -stored in a closed container. The encapsulation efficiency of Alg-GG was determined as follows [15]:

$$
\text { Efficiency of encapsulation }(\%)=\frac{\text { Loaded bromelian }}{\text { Initial bromelain }} \times 100 \%
$$

The bromelain-containing hydrogels were analyzed by FTIR.

\section{Dissolution profile test for bromelain}

The dissolution profile of bromelain was determined using the rotating basket method. The hydrogel beads containing bromelain were weighed and placed into a basket that is connected to a dissolution apparatus. In the first $2 \mathrm{~h}$, the basket was soaked in $500 \mathrm{~mL} \mathrm{HCl}-\mathrm{KCl}$ buffer solution (pH 1.2), which serves as an artificial gastric fluid medium, at $37^{\circ} \mathrm{C}$ and stirred at $100 \mathrm{rpm}$. Every $30 \mathrm{~min}, 10 \mathrm{~mL}$ solution was drawn out through the channel that connects to a syringe. In the next $4 \mathrm{~h}$, the basket was soaked in $500 \mathrm{~mL} 0.2 \mathrm{M}$ phosphate buffer ( $\mathrm{pH}$ 7.4), which serves as an artificial intestinal environment. In the first $2 \mathrm{~h}$, filtrate was taken every $30 \mathrm{~min}$; the next $2 \mathrm{~h}$, filtrate was taken every hour in. Every volume of solution drawn out from the medium was replaced with the same amount of fresh buffer [16]. The protein contents and proteolytic activities of the solution were determined using the Bradford and the Kunitz methods, respectively. The highest proteolytic activity of the solution was used in antiplatelet activity determination. The bromelain-loaded hydrogel was characterized by FTIR, SEM and optical microscopy.

\section{Determination of the dissolution kinetics of bromelain-loaded} Alg-GG

Data on encapsulation efficiency and dissolution of bromelain were applied into the zero-order, first-order, Higuchi, and Korsmeyer-Peppas models. These mathematical models were used to determine the mechanism and kinetics of bromelain dissolution from the hydrogel [9].

\section{Determination of in vitro antiplatelet activity}

The antiplatelet activity was determined by Born method to the fraction which has the highest specific activity [12]. In addition, acetosal and water were used as positive and negative controls, respectively. The platelet activity of the fraction obtained during the dissolution test was determined and compared with that of the dialysis fraction.

\section{RESULTS AND DISCUSSION}

\section{Isolation, salt precipitation, and dialysis of bromelain}

Crude bromelain solution, which is a clear pale yellow solution, was separated from the fiber and other impurities through centrifugation and filtration. The specific activity of bromelain was enhanced through precipitation using different concentrations of ammonium sulfate and sodium benzoate salt. The principle employed in protein precipitation is salting out. The water that dissolves protein is drawn out by salt, which displays a high solubility. As a result, the protein-solvent interaction is lower than the protein-protein interactions, causing the proteins to aggregate and form large molecules with very low solubility [17]. As shown in Table 1, the specific activity of ammonium sulfate is a significant difference with sodium benzoate. The specific activity of bromelain obtained through ammonium sulfate precipitation is higher than that of the bromelain obtained through sodium benzoate precipitation. This disparity is caused by the low solubility of sodium benzoate, causing it to settle at the bottom. Thus, the ability of sodium benzoate to remove water is decreased, and the bromelain obtained contains salt. This salt was removed through dialysis using a semipermeable membrane. The difference in concentrations between the buffers found on the two sides of the membrane causes the salt and small protein to diffuse out through the membrane. Moreover, the specific activity of the bromelain is increased after the dialysis (Table 2).

The proteolytic activity of the bromelain was measured at optimum condition, that is, at a casein substrate concentration of $1 \%$ [18]

\section{Synthesis of Alg-GG hydrogel}

The hydrogel solution was added into $0.5 \mathrm{M} \mathrm{CaCl}_{2}$ solution using an infusion set. The presence of $\mathrm{Ca}^{2+}$ triggers ionic interaction with carboxylate function at the guluronic segment, resulting in an egg box conformation [19]. Bivalent ions, such as $\mathrm{Pb}^{2+}, \mathrm{Cu}^{2+}, \mathrm{Ba}^{2+}$, and $\mathrm{Sr}^{2+}$, as well as trivalent ions also cause alginate to display such conformation. $\mathrm{Ca}^{2+}$ ion was chosen due to its characteristics are suitable and compatible for the human body. The chelating process occurs spontaneously, resulting in the formation of hydrogel beads. FTIR spectrum shows several transmittances, a characteristic of the functional group of sodium Alg-GG. The FTIR spectra of Alg-GG show a peak for O-H stretch bands at $3200-3600 \mathrm{~cm}^{-1}$, an asymmetric and an symmetric carboxylate salt ion stretch band at 1579 and $1400 \mathrm{~cm}^{-1}$, respectively, and ether group bands at $1220 \mathrm{~cm}^{-1}$. The characteristic band for mannuronic unit in the alginate appeared at $828 \mathrm{~cm}^{-1}$. The successful cross-linking reaction was confirmed by differences in the spectra of Alg-GG and glutaraldehydecrosslinked Alg-GG (Fig. 1).

The cross-linked hydrogel spectra showed a decreasing absorbance at $3600-3200 \mathrm{~cm}^{-1}$. This trend is caused by the formation of acetal, which converts two equivalents of hydroxide group from sodium Alg-GG into an ether group. Furthermore, an increasing absorbance was observed at $1220 \mathrm{~cm}^{-1}$, and this phenomenon is related to the formation of ether as a product of hydroxide from the hydrogel and of an aldehyde group from glutaraldehyde. In acidic condition, aldehydes will protonate to form carbocation with a hydroxide group at the side chain. Afterwards, the hydroxide group in Alg-GG will interact with the carbocation and then deprotonate to form a hemiacetal. The hydroxides group, which pairs with the hemiacetal, will reprotonate to form $-\mathrm{OH}_{2}{ }^{+}$as a good leaving group so that the dehydration reaction will occur to form a carbocation and an ether bond at the side chain. This reaction occurs to form as much as two equivalents of ether bonds or generally called acetal. 
Table 1: Results for the bromelain isolation and precipitation

\begin{tabular}{|c|c|c|c|c|c|c|}
\hline \multirow[t]{2}{*}{ Sample } & \multicolumn{3}{|l|}{ Total } & \multirow{2}{*}{$\begin{array}{l}\text { Specific activity } \\
\text { (U/mg) }\end{array}$} & \multirow{2}{*}{$\begin{array}{l}\text { Purification } \\
\text { levels (Times) }\end{array}$} & \multirow[t]{2}{*}{ Yield (\%) } \\
\hline & Volume (mL) & Protein (mg) & Proteolytic activity (U) & & & \\
\hline \multicolumn{7}{|c|}{ Ammonium sulfate precipitation } \\
\hline \multicolumn{7}{|c|}{ Homogenates were filtered at $\mathrm{T}=4^{\circ} \mathrm{C}$} \\
\hline Core solution & 400 & 91.2 & 2140 & 23.46 & - & - \\
\hline \multicolumn{7}{|c|}{ Centrifuged at $6000 \mathrm{rpm}, 45 \mathrm{~min}, \mathrm{~T}=4^{\circ} \mathrm{C}$} \\
\hline Crude enzyme & 385 & 61.2 & 3141.6 & 51.32 & 1 & 100 \\
\hline \multicolumn{7}{|c|}{ Precipitation of bromelain using ammonium sulfate $(n=3)$} \\
\hline F1 (0-20\%) & 5 & 0.47 & 78.65 & $167.34 \pm 3.76$ & 3.26 & 2.50 \\
\hline F2 (20-50\%) & 6 & 0.52 & 139.74 & $267.70 \pm 4.67$ & 5.22 & 4.45 \\
\hline F3 (50-80\%) & 1.10 & 0.08 & 6.58 & $75.69 \pm 1.67$ & 1.47 & 0.21 \\
\hline \multicolumn{7}{|c|}{ Sodium benzoate precipitation } \\
\hline \multicolumn{7}{|c|}{ Homogenates were filtered at $\mathrm{T}=4^{\circ} \mathrm{C}$} \\
\hline Core solution & 350 & 193.50 & 5168.10 & 26.70 & - & - \\
\hline \multicolumn{7}{|c|}{ Centrifuged at $6000 \mathrm{rpm}, 45 \mathrm{~min}, \mathrm{~T}=4^{\circ} \mathrm{C}$} \\
\hline Crude enzyme & 310 & 83.08 & 5450.73 & 65.49 & 1 & 100 \\
\hline \multicolumn{7}{|c|}{ Precipitation of bromelain using sodium benzoate $(n=3)$} \\
\hline F1 (0-20\%) & 5.50 & 1.07 & 97.53 & $90.77 \pm 3.44$ & 1.39 & 1.79 \\
\hline F2 (20-50\%) & 6 & 0.92 & 126.49 & $115.63 \pm 3.35$ & 1.77 & 2.32 \\
\hline F3 (50-80\%) & 2 & 0.14 & 12.27 & $87.19 \pm 2.87$ & 1.33 & 0.26 \\
\hline
\end{tabular}

Table 2: Results for bromelain activities after dialysis

\begin{tabular}{|c|c|c|c|c|c|c|}
\hline \multirow[t]{2}{*}{ Sample } & \multicolumn{3}{|l|}{ Total } & \multirow{2}{*}{$\begin{array}{l}\text { Specific activity } \\
\text { (U/mg) }\end{array}$} & \multirow{2}{*}{$\begin{array}{l}\text { Purification levels } \\
\text { (Times) }\end{array}$} & \multirow[t]{2}{*}{ Yield (\%) } \\
\hline & Volume (mL) & Protein (mg) & Proteolytic activity (U) & & & \\
\hline $\begin{array}{l}\text { F2 before dialysis } \\
\text { Dialysis for } 20 \mathrm{~h}, \mathrm{~T}=4\end{array}$ & $\begin{array}{l}6 \\
{ }^{6} \mathrm{C}\end{array}$ & 0.52 & 139.74 & 267.70 & 5.22 & 4.44 \\
\hline F2 after dialysis & 7 & 0.50 & 167.44 & 332.22 & 6.47 & 5.33 \\
\hline
\end{tabular}

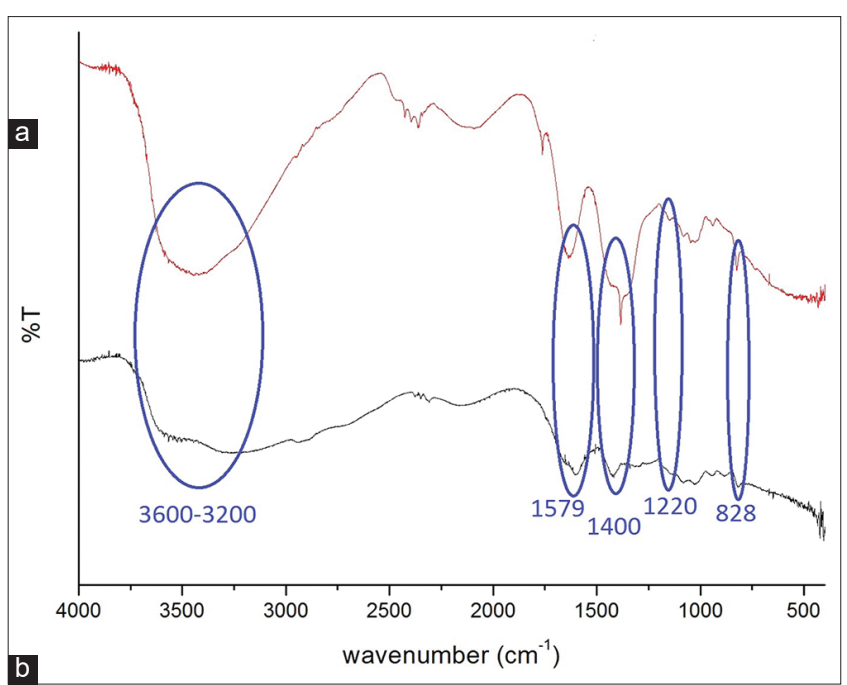

Fig. 1: Fourier-transform infrared spectra of (a) alginate-guar gum and (b) glutaraldehyde-crosslinked alginate-guar gum

\section{Swelling ratio of Alg-GG hydrogel}

The hydrogels were soaked for only $30 \mathrm{~min}$ to maintain their shapes so that the weighting process can be easily done. The swelling ratios for each variation are presented in Fig. 2, which shows that the swelling ratio of the hydrogel is lower at $\mathrm{pH} 1.2$ than at $\mathrm{pH}$ 7.4.

When the $\mathrm{pH}$ is lower than the pKa, which is 3.4, the carbocyclic group at the alginate chain exists in an acid form $(-\mathrm{COOH})$. By contrast, when the $\mathrm{pH}$ is higher than the $\mathrm{pKa}$, the carbocyclic group is ionized into $-\mathrm{COO}^{-}$, resulting in the repulsion between these groups and in the stretching of the polymers. The maximum stretch is reached at approximately pH 7.4 [20]. As shown in Fig. 2, the swelling ratio of the hydrogel in both acidity levels decreases with the increasing amount of glutaraldehyde.

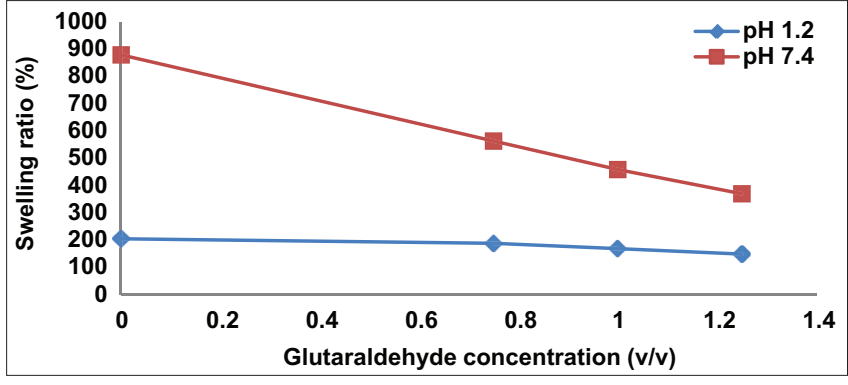

Fig. 2: Swelling ratio of the hydrogel in artificial gastric fluid (pH 1.2) and intestinal environment (pH 7.4)

Cross-linking in the alginate renders the hydrogel denser, causing the hydrogel to absorb a limited amount of liquid. Furthermore, the crosslinking reaction enhances the mechanical endurance of the hydrogel, making it more stiff and resistant to deformation caused by external forces.

\section{Bromelain-loaded Alg-GG}

Encapsulation of bromelain in cross-linked Alg-GG was conducted through the post-loading method, wherein the hydrogel beads were soaked in bromelain solution of different concentrations. Freeze-drying method was used to remove water from the hydrogel, to maintain the bromelain activity, and to avoid the bromelain degradation due to high temperature. Freeze drying is a drying process involving sublimation under vacuum condition. The Alg-GG hydrogel beads before and after encapsulation were characterized by FTIR, and the results are shown in Fig. 3. Based on the FTIR spectra in Fig. 3, no difference was observed between the peaks of Alg-GG and Alg-GG-loaded bromelain, indicating that there is no chemical interaction between bromelain and the hydrogel.

However, the absorption intensity at $3200-3600 \mathrm{~cm}^{-1}$ has changed due to a physical interaction (hydrogen bond interaction) [11]. Such 
a physical interaction may have caused the bromelain to easily diffuse throughout the hydrogel.

\section{Efficiency of bromelain encapsulation in Alg-GG}

Encapsulation with the hydrogel containing $0.75 \%$ glutaraldehyde was performed using the post-loading method. The protein levels of the bromelain solution that was not absorbed by the hydrogel were determined by the Bradford method. This method was used due to its lower limit detection and higher sensitivity than the Lowry method [21]. In the Bradford method, Coomassie Brilliant Blue G-250 dye binds with the hydrophobic site of protein under acidic condition. It yields a deep blue color complex that has a maximum absorbance at $595 \mathrm{~nm}$. The color obtained is relatively stable for as long as an hour and is not affected by impurities, such as carbohydrate, alkali ion, or buffer [22]. Such stability is caused by the strong hydrophobic and ionic interactions between anion shapes in the pigment and in the protein. The graph showing the encapsulation efficiency of each bromelain concentration is presented in Fig. 4, which shows that the encapsulation efficiency decreases with increasing enzyme concentration.

This pattern is attributed to the capacity of the hydrogel to absorb a limited amount of bromelain. As a result, the remaining bromelain solution still contains a high bromelain concentration, which reduces the efficiency of bromelain encapsulation. The highest efficiency of the hydrogel to encapsulate bromelain with $70 \mathrm{ppm}$ concentration is $72.2 \%$.

\section{Physical analysis of bromelain-loaded Alg-GG}

The morphological features of the hydrogel were analyzed using SEM at several magnifications (Fig. 5). Fig. 5 shows that the hydrogel beads are not perfectly round with rough surfaces. When the hydrogel beads were oven-dried, they stick strongly to one another so that they needed to be separated one by one. The hydrogels are approximately $\pm 1 \mathrm{~mm}$ to

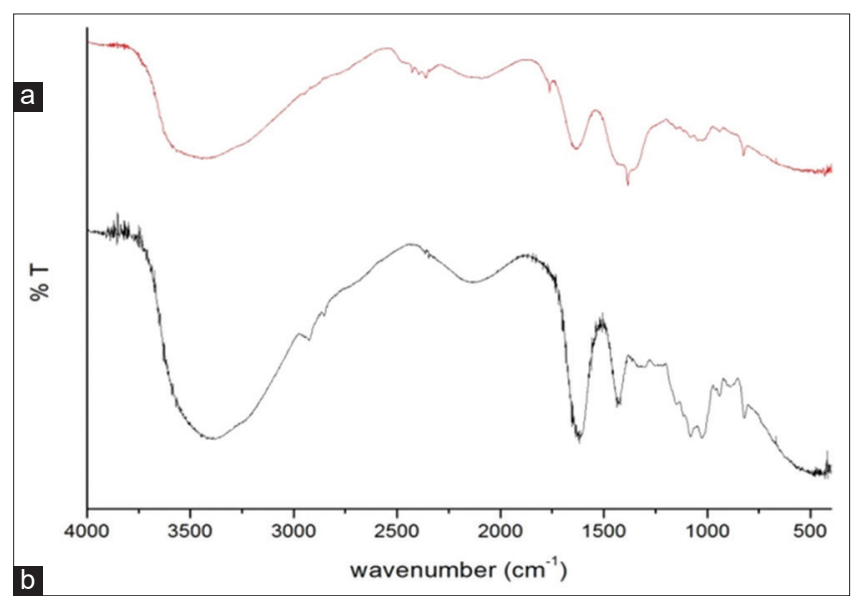

Fig. 3: Fourier-transform infrared spectra of the glutaraldehydecrosslinked alginate guar-gum (a) before encapsulation and (b) after encapsulation

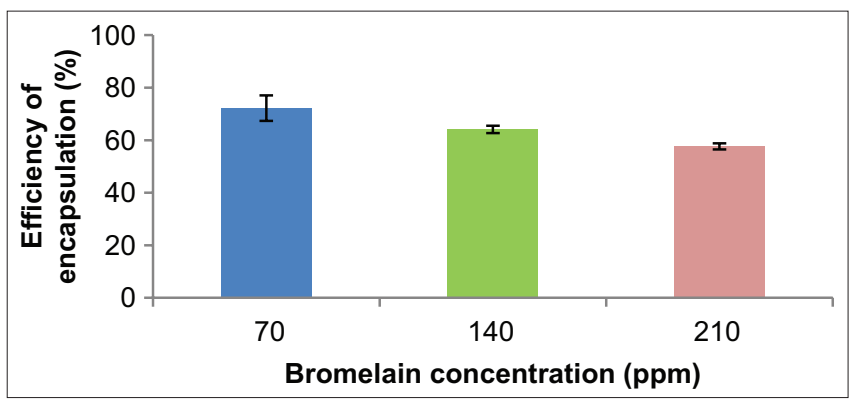

Fig. 4: Encapsulation efficiency of different bromelain concentrations $(n=3)$ $\pm 1.6 \mathrm{~mm}$ in size. The internal morphology of the hydrogel was observed by cutting the hydrogel transversely. Analysis of the cross-section of the hydrogel revealed the presence of $\pm 600 \mathrm{~nm}$ pores inside the hydrogel. The pores serve as the entry point of bromelain during its absorption into the hydrogel. Moreover, there are bromelains that spread evenly and with a brighter color than the others (Fig. 5).

After the dissolution test, the hydrogel beads were characterized using an optical microscope. After incubation for $2 \mathrm{~h}$ in an artificial gastric fluid and for $5 \mathrm{~h}$ in an artificial intestinal environment, the hydrogel beads were analyzed under an optical microscope at $45 \times$ (Fig. 6). The hydrogel incubated in the artificial gastric fluid was swollen into a rounded shape, and it remained solid in acidic condition. By contrast, the hydrogel incubated in the artificial intestinal environment was maximally swollen, and it lost its solid form [20]. As shown in Fig. 6, the hydrogel surface erodes, creating a hole in the hydrogel matrix through which the bromelain exits.

Dissolution test for bromelain encapsulated in Alg-GG hydrogel A dissolution test was performed for $2 \mathrm{~h}$ in an artificial gastric fluid $(\mathrm{pH} 1.2)$ and for $4 \mathrm{~h}$ in an artificial intestinal environment ( $\mathrm{pH}$ 7.4). The movement of hydrogel beads from the artificial gastric fluid to the intestinal environment was easily facilitated using the basket dissolution method. This method prevents a broken hydrogel from diffusing out into the test solution, which may clog the sample collection channel. Fig. 7 shows the curves of proteolytic activity and protein content of the dissolution filtrate.
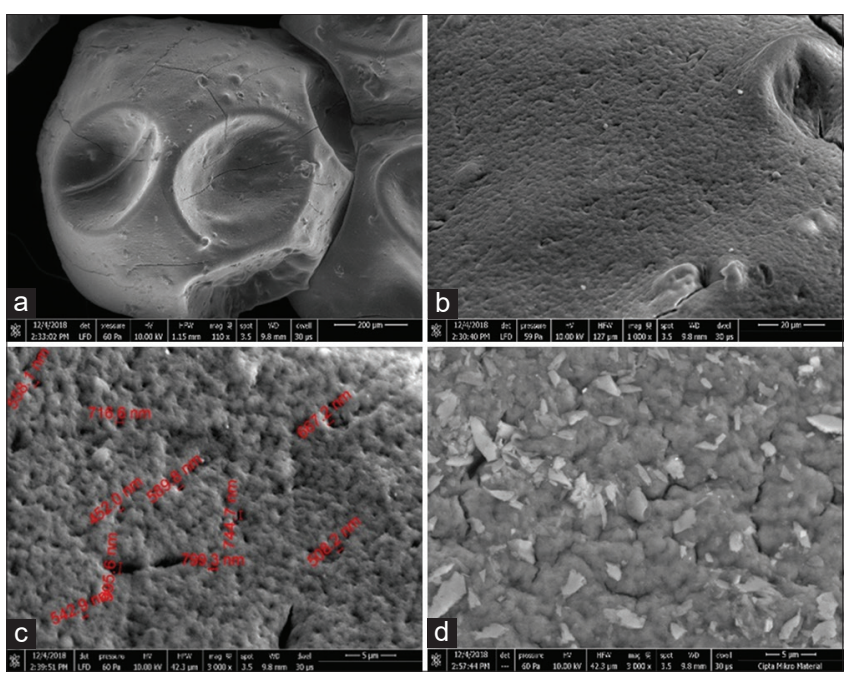

Fig. 5: Scanning electron microscopy characterization of the glutaraldehyde-crosslinked alginate guar-gum: (a) Surface, $\times 110$ (b) cross-section, $\times 1000$; (c) size of pores of the hydrogel used to encapsulate bromelain, $\times 3000$; (d) cross-section of the hydrogel used to encapsulate bromelain, $\times 3000$
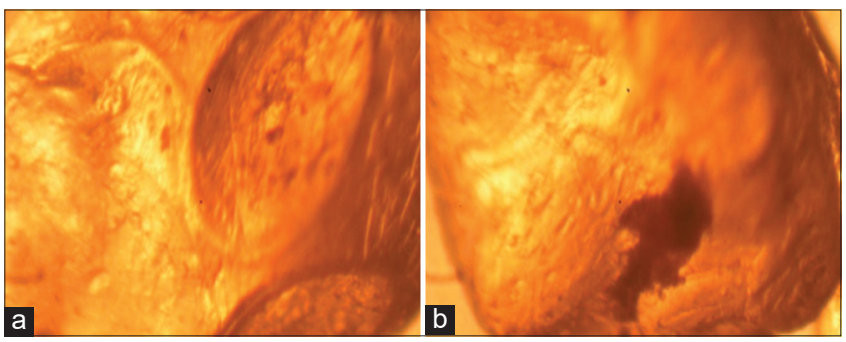

Fig. 6: Microscopic characterization at 45 magnification of glutaraldehyde-crosslinked alginate guar-gum used to encapsulate bromelain in the (a) artificial gastric fluid (pH 1.2) and (b) intestinal environment $(\mathrm{pH} 7.4)$ 
Table 3: Kinetics and mechanism of bromelain dissolution

\begin{tabular}{|c|c|c|c|c|c|c|}
\hline \multirow[t]{3}{*}{ Concentration } & \multirow[t]{3}{*}{ Parameter } & \multicolumn{5}{|l|}{ Model } \\
\hline & & \multicolumn{3}{|c|}{ Kinetics of dissolution } & \multirow{2}{*}{\multicolumn{2}{|c|}{$\begin{array}{l}\text { Mechanism of dissolution } \\
\text { Korsmeyer-Peppas }\end{array}$}} \\
\hline & & Zero-order & First-order & Higuchi & & \\
\hline \multirow{3}{*}{$70 \mathrm{ppm}$} & $\mathrm{R}^{2}$ & 0.96 & 0.98 & 0.95 & 0.99 & Erosion \\
\hline & $\mathrm{K}$ & 0.23 & $6.10 \times 10^{-3}$ & 5.18 & 0.30 & \\
\hline & $\mathrm{n}$ & - & - & - & 0.99 & $\mathrm{n}>0.89$ \\
\hline \multirow[t]{3}{*}{$140 \mathrm{ppm}$} & $\mathrm{R}^{2}$ & 0.96 & 0.96 & 0.95 & 0.98 & Diffusion and erosion \\
\hline & $\mathrm{K}$ & 0.23 & $6.73 \times 10^{-3}$ & 5.22 & 0.53 & \\
\hline & $\mathrm{n}$ & - & - & - & 0.88 & $0.45<\mathrm{n}<0.89$ \\
\hline \multirow[t]{3}{*}{$210 \mathrm{ppm}$} & $\mathrm{R}^{2}$ & 0.96 & 0.93 & 0.96 & 0.98 & Diffusion and erosion \\
\hline & $\mathrm{K}$ & 0.24 & $7.83 \times 10^{-3}$ & 5.32 & 0.79 & \\
\hline & $\mathrm{n}$ & - & - & - & 0.81 & $0.45<\mathrm{n}<0.89$ \\
\hline
\end{tabular}

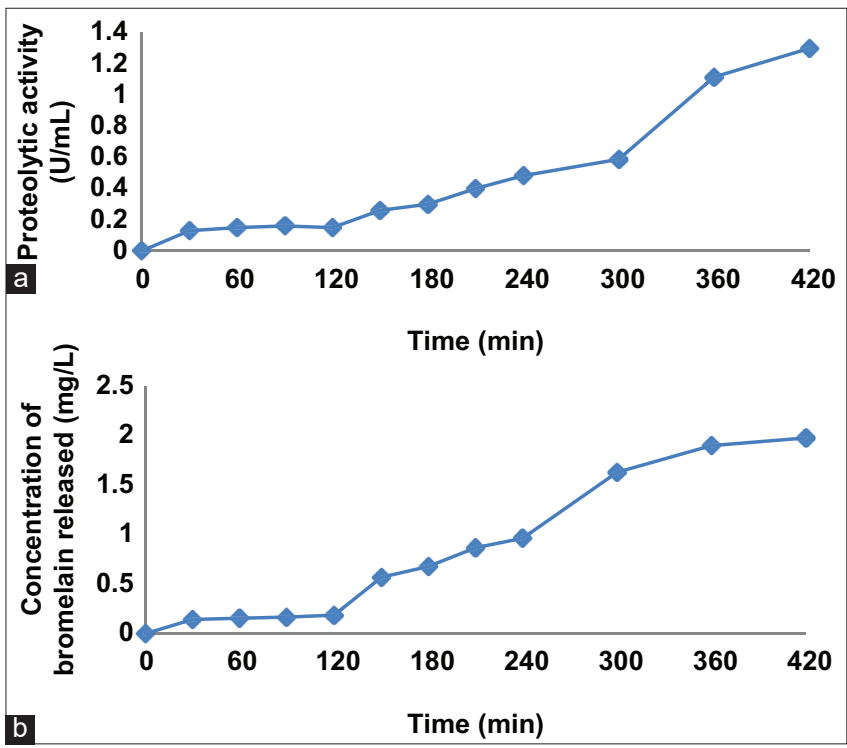

Fig. 7: Dissolution test result curves: (a) Proteolytic activity versus time; (b) concentration of bromelain released versus time

The results show that the release of bromelain into the intestinal environment is higher than its release into the artificial gastric fluid. Moreover, the maximum protein content is considerably smaller in the artificial gastric fluid $(0.18 \mathrm{mg} / \mathrm{L})$ than in the intestinal environment $(1.97 \mathrm{mg} / \mathrm{L})$. The protein release into the intestinal environment is affected by swelling of the hydrogel [23]. Its high swelling ability causes the trapped bromelain to easily diffuse out through the pores. The dissolution profile of the hydrogel tends to increase until it reaches its maximum at $420 \mathrm{~min}$ before it completely dissolves.

Influence of bromelain concentration on the dissolution mechanism

The mechanism of dissolution can be determined by applying the data on dissolution into such mathematical models as zero-order, firstorder, Higuchi, and Korsmeyer-Peppas models [9]. Table 3 shows the dissolution kinetics of the bromelain encapsulated in Alg-GG hydrogels. The determination of the suitable dissolution model from several mathematical models is based on the regression coefficient value or $R^{2}[10]$. Table 3 shows that based on the highest $R^{2}$ value, the dissolution profile of each concentration follows the same model, that is, the Korsmeyer-Peppas model; in this model, the dissolution is influenced by the $n$ (exponential) value.

The $\mathrm{n}$ value is a kinetics constant that is dependent on bromelain transport mechanism characterization. When the $\mathrm{n}$ value falls within the range $0.45<\mathrm{n}<0.89$, the mechanism of bromelain dissolution is based on non-Fickian or anomalous diffusion (combination of diffusion

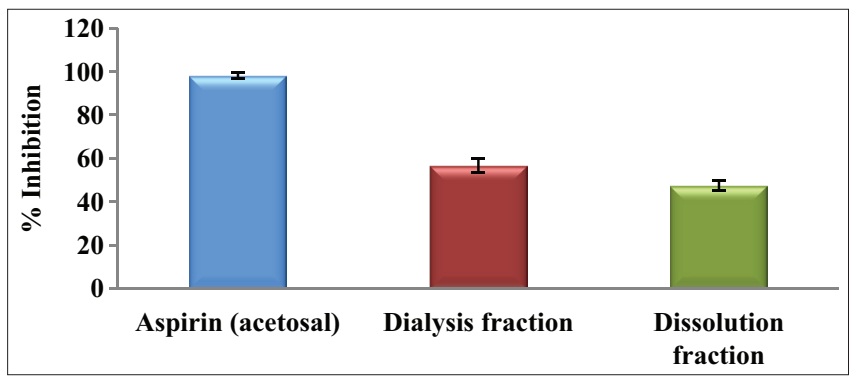

Fig. 8: Antiplatelet aggregation activity of bromelain fraction $(n=3)$

and erosion). Bromelain dissolution occurs due to the entry of the dissolution medium into the hydrogels followed by hydrogel erosion and then the release of bromelain [10]. Hydrogel erosion is confirmed through microscopic observation (Fig. 6). Fig. 6 shows that the hydrogel surface is eroded, allowing the bromelain to flow out into the media solution. The kinetics of dissolution rate (K value) of the bromelain was higher at $210 \mathrm{ppm}(\mathrm{K}=0.79)$ than at $140 \mathrm{ppm}(\mathrm{K}=0.53)$ and $70 \mathrm{ppm}$ $(\mathrm{K}=0.30)$. At $210 \mathrm{ppm}$, bromelain is not absorbed deeply into the hydrogel and thus diffuses out easily during dissolution. Hence, the bromelain exits through the pores that have been opened. By contrast, at $70 \mathrm{ppm}$, the dissolution is slower than in the other concentrations due to the absorption of bromelain deep into core of the hydrogel.

\section{Antiplatelet activity determination}

Antiplatelet activity refers to the inhibitory activity of compounds against platelet aggregation. In this study, the antiplatelet activity test was conducted by observing the percentage of platelet aggregation and of inhibition. The percentage of inhibition is the ability of a compound to inhibit thrombus formation. A compound with a good antiplatelet activity has a low percentage of platelet aggregation and a high percentage of inhibition. The antiplatelet activity of the bromelain obtained through dialysis and dissolution was determined by the Born method. In this method, the absorbance of the plasma containing bromelain was compared before and after the addition of an aggregator compound. The absorbance of the solution without aggregator is high due to the homogenous distribution of platelets in the plasma solution. When an aggregator was added into the solution, the platelets aggregated and settled at the bottom of the tube, causing the absorbance to decrease. The poor ability of the bromelain to inhibit platelet aggregation is indicated by the significant decrease in absorbance. Acetosal $(1 \mathrm{mg} / \mathrm{mL})$ and water were used as positive and negative controls, respectively. Acetosal is a commercial antiplatelet drug, and its mechanism of platelet aggregation inhibition is similar to that of bromelain. The mechanism involves the inactivation of the cyclooxygenase enzyme, which acts as a catalyst of thromboxane A2 formation. The thromboxane A2 helps thrombocynase to convert prothrombin into thrombin, one of the agents that trigger platelet aggregation. Adenosine 5'-diphosphate is used as an aggregator that activates phospholipase A2 to catalyze the arachidonic acid formation. 
Arachidonic acid is a precursor for thromboxane A2. The saline solution consists of $0.9 \%(\mathrm{w} / \mathrm{v}) \mathrm{NaCl}$, which represents the body fluids. Saline solution is used as a blood-thinning agent to increase the volume of the blood solution for UV-visible spectrophotometric measurements. The test results are presented in Fig. 8, which shows that the dissolution fraction has a lower percentage of inhibition compared with the dialysis fraction. This finding is attributed to the slight loss in bromelain activity during the dissolution process.

\section{CONCLUSION}

The specific activity of the bromelain precipitated using ammonium sulfate is higher than that of the bromelain precipitated using sodium benzoate. The specific activity of bromelain is further increased by the dialysis process. The purified bromelain was successfully encapsulated in Alg-GG hydrogel through the post-loading method for the dissolution tests. The release of bromelain through dissolution and the proteolytic activity of bromelain were higher in artificial intestinal environment than in artificial gastric fluid. The dissolution mechanism of bromelain encapsulated in Alg-GG hydrogel follows the Korsmeyer-Peppas model, wherein the mechanism is a combination of erosion and diffusion. The dissolution fraction of bromelain displays antiplatelet aggregation activity.

\section{ACKNOWLEDGMENT}

This research was financially supported by the Penelitian Dasar Unggulan Perguruan Tinggi 2019 Program of the Ministry of Research, Technology and Higher Education of the Republic of Indonesia.

\section{AUTHORS' CONTRIBUTIONS}

Prof. Sumi Hudiyono, Dr. Emil Budiono, and Dra. Siswati Setiasih Apt., M.S., the guarantor of this study has designed and supervised the experimental process. Mr. Fakhrian Juliano S. Si has carried out the experiments and analyzed the results. Mr. Hegi Adi Prabowo S. Si contributed to preparation and revision of the manuscript.

\section{CONFLICTS OF INTEREST}

The authors declare that they have no conflicts of interest.

\section{REFERENCES}

1. Cardiovascular Division and Health Service Centre. Reducing the Burden of CVD In Indonesia. Newtown: The George Institute for Global Health; 2017.

2. ISTH Steering Committee for World Thrombosis Day. Thrombosis: A major contributor to the global disease burden. J Thromb Haemost 2014;12:1580-90.

3. Kim HJ, Lee YH, Im SA, Kim K, Lee CK. Cyclooxygenase inhibitors, aspirin and ibuprofen, inhibit mhc-restricted antigen presentation in dendritic cells. Immune Netw 2010;10:92-8.

4. Huang ES, Strate LL, Ho WW, Lee SS, Chan AT. Long-term use of aspirin and the risk of gastrointestinal bleeding. Am J Med $2011 ; 124: 426-33$.
5. Sub-directorate of Horticulture Statistics. Statistics of Annual Fruit and Vegetable Plants Indonesia. Jakarta: BPS Statistics Indonesia; 2017.

6. Bhattacharyya BK. Bromelain: An overview. Nat Prod Rad 2008;7:359-63.

7. Setiasih S, Darwis AA, Dzikria V, Hudiyono S. Stability test of partially purified bromelain from pineapple (Ananas comosus (L.) Merr) core extract in artificial stomatch fluid. IOP Conf Ser 2018;299:1-7.

8. Chobotova K, Vernallis AB, Majid FA. Bromelain's activity and potential as an anti-cancer agent: Current evidence and perspectives. Cancer Lett 2010;290:148-56.

9. Shaikh HK, Kshirsagar RV, Patil SG. Mathematical models for drug release characterization: A review. World J Pharm Pharm Sci 2015;4:324-38.

10. Shoaib MH, Tazeen J, Merchant HA, Yousuf RI. Evaluation of drug release kinetics from ibuprofen matrix tablets using HPMC. Pak J Pharm Sci 2006;19:119-24.

11. Setiasih S, Prabowo HA, Budianto E, Hudiyono S. Dissolution profiles of partially purified bromelain from pineapple cores [Ananas comosus (L.) Merr] encapsulated in glutaraldehyde-crosslinked chitosan. J Appl Pharm Sci 2018;8:17-24.

12. Musfiroh FF, Setiasih S, Handayani S, Hudiyono S, Ilyas NM. In vivo antiplatelet activity aggregation assay of bromelain fractionate by ethanol from extract pineapple core (Ananas comosus [L.] Merr). IOP Conf Ser 2018;299:1-4.

13. George M, Abraham TE. $\mathrm{pH}$ sensitive alginate-guar gum hydrogel for the controlled delivery of protein drugs. Int J Pharm 2007;335:123-9.

14. Selvakumaran S, Muhamad II, Abd Razak SI. Evaluation of kappa carrageenan as potential carrier for floating drug delivery system: Effect of pore forming agents. Carbohydr Polym 2016;135:207-14.

15. Zhu Z, Li Y, Li X, Li R, Jia Z, Liu B, et al. Paclitaxel-loaded poly(Nvinylpyrrolidone)-b-poly(epsilon-caprolactone) nanoparticles: Preparation and antitumor activity in vivo. J Control Release 2010;142:438-46.

16. Logoyda L, Kovalenko S, Abdel-Megied AM, Zhulkevych I, Drapak I, Demchuk I, et al. HPLC method development for the analysis of bisoprolol in combined dosage form containing bisoprolol and enalapril and in vitro dissolutions studied. Int J Appl Pharm 2019;11:186-94.

17. Reece JB, Campbell NA, Meyers N, Urry LA, Cain ML, Wasserman SA, et al. Campbell Biology. $9^{\text {th }}$ ed. French Forest: Pearson Australia; 2011.

18. Fadhilah Y, Shoobihah A, Setiasih S, Handayani S, Hudiyono S. The Effect of $\mathrm{Ca}^{2+}, \mathrm{Mg}^{2+}$ ions, cysteine, and benzoic acid on the activity of purified bromelain from pineapple core extract (Ananas comosus [L] Merr). AIP Conf Proc 2018;2049:20029.

19. Lee KY, Mooney DJ. Alginate: Properties and biomedical applications. Prog Polym Sci 2012;37:106-26.

20. Agüero L, Zaldivar-Silva D, Peña L, Dias ML. Alginate microparticles as oral colon drug delivery device: A review. Carbhohydr Polym 2017; 168:32-43.

21. Redmile-Gordon MA Armenise E, White RP, Hirsch PR, Goulding KW. A comparison of two colorimetric assays, based upon Lowry and Bradford techniques, to estimate total protein in soil extracts. Soil Biol Biochem 2013;67:166-73.

22. Bradford MM. A rapid and sensitive method for the quantitation of microgram quantities of protein utilizing the principle of protein-dye binding. Anal Biochem 1976;72:248-54.

23. Caccavo D, Cascone S, Lamberti G, Barba AA, Larsson A. Swellable hydrogel-based system for controlled drug delivery. In: Sezer AD, editor. Smart Drug Delivery System. London: InTech; 2016. p. 237-303. 